\title{
Post-Combustion Capture or Direct Air Capture in Decarbonizing US Natural Gas Power?
}

\author{
Habib Azarabadi ${ }^{a}$, Klaus S Lackner ${ }^{\mathrm{a}}$ \\ ${ }^{a}$ School of Sustainable Engineering \& the Built Environment, Arizona State University, Tempe, AZ
}

\begin{abstract}
:
This analysis investigates the cost of carbon capture from the US natural gas-fired electricity generating fleet comparing two technologies: Post-Combustion Capture and Direct Air Capture (DAC). Many Natural Gas Combined Cycle (NGCC) units are suitable for post-combustion capture. We estimated the cost of post-combustion retrofits and investigated the most important unit characteristics contributing to this cost. Units larger than $350 \mathrm{MW}$, younger than 15 years, more efficient than $42 \%$ and with a utilization (capacity factor) higher than 0.5 are economically retrofittable. Counterintuitively, DAC (which is usually not considered for point-source capture) may be cheaper in addressing emissions from non-retrofittable NGCCs. DAC can also address the residual emissions from retrofitted plants. Moreover, economic challenges of post-combustion capture for small natural gas-fired units with low utilization, such as gas turbines, make DAC look favorable for these units. Considering the cost of post-combustion capture for the entire natural gas-related emissions after incorporating the impact of learning-by-doing for both carbon capture technologies, DAC is the cheaper capture solution for at least $1 / 3$ of all emissions.
\end{abstract}

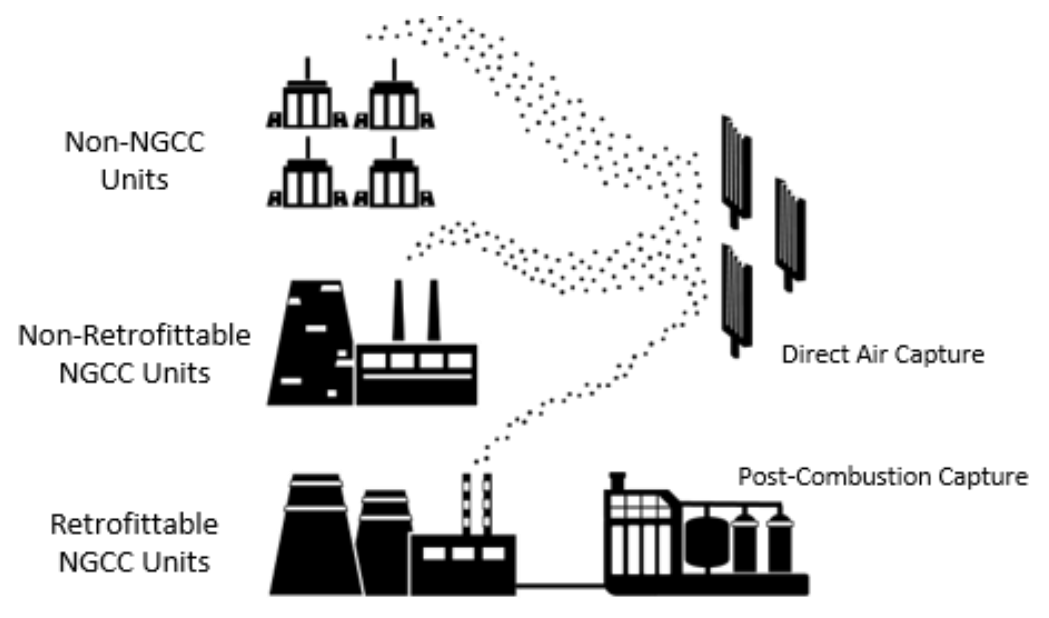




\section{Introduction and Objectives:}

In the United States utility level electricity emissions, although on a gradual declining path, contributed about a third of total greenhouse gas emissions ${ }^{1}$. The replacement of coal with cheap unconventional natural gas is the primary reason for the recent reduction in the $\mathrm{US}_{\mathrm{CO}_{2}}$ emission ${ }^{2}$, increasing the importance of natural gas power as a source of greenhouse gas emissions. In spite of the current reduction in emissions, the United States, along with other industrial countries, is not on a path to deliver the promises made in Paris ${ }^{3}$.

The main effort in the decarbonization of dispatchable electricity generation has been focused on Carbon Capture and Storage (CCS) in the form of post-combustion capture with liquid sorbents. Due to its similarity to other pollution control technologies, post-combustion capture technology is more mature than other forms of CCS. Even though it lends itself to retrofitting existing plants, postcombustion capture is usually considered for new power plants. The cost of retrofitting existing power plants is generally higher than the cost of incorporating CCS into a new plant ${ }^{4}$. Nevertheless, under the aggressive scenarios for decarbonization considered today ${ }^{5}$, retrofitting existing plants will be important. Rubin and colleagues investigated the decarbonization potential of the US coal-fired power plant fleet through retrofit with commercially available amine-scrubbing post-combustion systems ${ }^{6}$. Assuming a $30 \% \mathrm{CO}_{2}$ removal goal, which is in line with the Environmental Protection Agency's (US EPA) Clean Power Plant proposal established in $2014^{7}$, for each coal-fired generating unit in the 2010 US electricity grid, they concluded that 98 out of 627 units, or $24 \%$ equivalent of the US coal-fired fleet capacity is suitable for retrofit. Their study considers a plant retrofittable if its Levelized Cost of Electricity (LCOE) ${ }^{8}$ after retrofit is lower than or equal to the LCOE of a benchmark new NGCC plant. Plants with higher capacity and utilization levels that are substantially amortized and can continue to operate for more than 20 years were identified as the most promising choices for CCS retrofit. An important outcome of this study was that the majority of the existing coal-fired power plants are ill-suited for post-combustion capture retrofit. This is not only due to their low efficiency or old age but also due to the low utilization level of many of these plants.

Despite the lower carbon-intensity of natural gas-fired electricity, a conversion from coal to natural for electricity generation falls far short of stabilizing the $\mathrm{CO}_{2}$ concentration in air. Natural gas power plants in the US are not generally considered for post-combustion capture; however, the majority of the natural gas generation capacity (and emissions) comes from Natural Gas Combined Cycle (NGCC) plants which could be equipped with post-combustion capture for emission reduction ${ }^{9}$. About $80 \%$ of natural 
gas electricity generation is from NGCC plants and the remainder comes from a large number of gas and steam turbines with small capacities that are not typically considered for carbon capture ${ }^{10}$. Gas turbines are extensively used to generate electricity during peak hours but sit idle most of the time.

This work investigates the true potential of post-combustion capture technology for decarbonization of the US natural gas-fired electricity from an economic perspective and assesses the opportunity for an unconventional CCS technology, Direct Air Capture (DAC), to address the residual emissions. DAC removes $\mathrm{CO}_{2}$ directly and can, therefore, address emissions from any source.

By collecting unit-level information for the existing natural gas-fired electricity generating units, the cost of retrofit with post-combustion capture was calculated for each unit and was compared to the cost of DAC. The cost of DAC was occasionally found to be cheaper than post-combustion capture, despite the thermodynamically greater difficulty of separating $\mathrm{CO}_{2}$ from the air rather than flue gas ${ }^{11}$.

In the next step, cost reductions as a result of "learning-by-doing" were incorporated into the comparison between power plants' retrofit and DAC. The path to scale-up and the resulting cost reductions due to learning are fundamentally different for post-combustion capture and DAC. Postcombustion capture units are inherently custom-made to match the specific plant and flue gas stream they are designed for, while DAC units are stand-alone and process a consistent feed of $\mathrm{CO}_{2}$ from the air. Accounting for the fundamentally different scale-up approaches, we projected the future cost of the two technologies when implemented at scale.

Lastly, we use the projected future costs to work out an example of total decarbonization of the US natural gas fleet by a combination of the two capture technologies. We argue that post-combustion capture alone is not sufficient for deep decarbonization and there exists an optimum combination of the two technologies which minimizes the total cost of decarbonization. 


\section{Material and Methods}

The Generation Resource Integrated Database (eGRID) ${ }^{10}$ was the primary source of data for this analysis. The cost of post-combustion capture retrofit was estimated for the existing NGCC units. Then the cost of retrofit was compared with different Direct Air Capture cost scenarios from commercial-scale plants in the literature.

In the next step, we incorporated learning-by-doing for both DAC and post-combustion. Experience curves from the literature and for similar technologies were utilized in this comparison and multiple learning scenarios were developed.

\section{Power Plant Databases:}

Typically, an NGCC unit has one or more Combustion Turbines (CT) and usually one Steam Turbine (ST). A power plant complex may have one or multiple NGCC units and each NGCC unit has multiple CTs and STs. eGRID 2016 includes granular data for each CT and ST attached to the US electricity grid. The initial database was further processed to obtain a complete data record for each NGCC unit. Each record includes a unit's characteristics (nameplate capacity, age, location) as well as its 2016 operational information (electricity generation, heat input, $\mathrm{CO}_{2}$ emissions). More on datamining and statistical information of NGCC units can be found in section S1 of the Supporting Information (SI).

Our database includes 670 NGCC units. We used each unit's characteristics such as age, nameplate capacity (NAMEPCAP) and net efficiency in addition to the unit's utilization level or capacity factor (CF) to estimate its cost of retrofit. The capacity factor is a measure of the utilization level of a power generating unit calculated as:

$$
C F=\frac{\text { Annual Electricity Generation }}{\text { Maximum Possible Annual Generation }}=\frac{\operatorname{GENNTAN}(M W h)}{\operatorname{NAMEPCAP}(M W) \times 8766(h)}
$$

GENNTAN is the amount of electricity generated by a unit in one year. According to the United States EPA, units with $C F<0.2$ are considered to be peakers and those with $C F>0.8$ are considered baseload ${ }^{10}$. Figure S2 plots the cumulative generation and the cumulative number of units below a given capacity factor for US NGCC and non-NGCC electricity generation in 2016 as a function of the capacity factor. Missing data in the original database (eGRID 2016) invalidate some of the NGCC records. 513 out of 670 data records were identified as valid and used for the calculations. See section S1 of the SI for more details about the assumptions in our data analysis, and section $\mathrm{S} 2$ for a validation analysis by a machine 
learning algorithm. Results from the validation analysis show that excluding the invalid datapoints does not cause a significant error in the final analysis.

Only units larger than $25 \mathrm{MW}$ and younger than 25 years old were considered for retrofit in this analysis (retrofittable units). This translates to 462 out of the 513 NGCC units, which provide $95 \%$ of the total NGCC generation capacity and $96 \%$ of the NGCC electricity generation.

\section{Retrofit Cost Calculation:}

The Integrated Environmental Control Model (IECM, version 11.2) ${ }^{12}$, developed by Carnegie Mellon University, is a power plant cost analysis tool for different types of fossil fuel power plants with various environmental control units. Considering the amine-scrubbing technology for post-combustion, we adopted IECM and its cost information to build a cost model for NGCC units and their retrofits. The cost model allows us to estimate the cost of avoided $\mathrm{CO}_{2}$.

To develop the cost model, we assumed the maximum input heat rate (or power block capacity) of each NGCC unit remains constant after retrofit; however, it suffers an energy penalty equivalent to a reduction by 7 percentage points in the net efficiency due to retrofit ${ }^{9}$. As an example, retrofitting an NGCC unit with a net efficiency of $50 \%$ results in a unit with a net efficiency of $43 \%$. All efficiency values in this analysis are based on higher heat values or HHV.

The internal heat and electricity consumption for the amine-scrubber is responsible for the efficiency loss. The energy penalty reduces the maximum available capacity (nameplate capacity) for electricity generation in each unit. We assumed a similar level of annual electricity generation for each unit after retrofit (to prevent generation loss in the grid). Given the lower available capacity, the capacity factor of the units increases after the retrofit.

Table 1 summarizes the important assumptions and parameters used in the model. The unit retirement age and maximum economic book life (amortization duration) were both set to 30 years. The economic book life of the post-combustion capture equipment installed for each unit was assumed to be equal to the remaining lifetime of that unit. A retrofit cost factor ranging between 1 and 1.25 has been suggested to capture the additional cost and site-specific difficulties of retrofit for existing power generating units $^{13}$. We assumed a constant retrofit cost factor of 1.15 for the NGCC fleet. Assumptions and parameters not listed in Table 1 are set to IECM default ${ }^{12}$.

The Cost of $\mathrm{CO}_{2}(\mathrm{COC})$ avoided is estimated by comparing the Levelized Cost of Electricity between the reference $\left(L C O E_{\text {ref }}\right)$ and the retrofitted unit $\left(L C O E_{\text {retrofit }}\right)^{14}$ : 


$$
\operatorname{COC}\left(\$ / \text { ton } \mathrm{CO}_{2}\right)=\frac{L C O E_{\text {retrofit }}-L C O E_{\text {ref }}(\$ / M W h)}{R O E_{\text {ref }}-R O E_{\text {retrofit }}\left(\operatorname{ton} \mathrm{CO}_{2} / \mathrm{MWh}\right)}
$$

$R O E$ is the rate of $\mathrm{CO}_{2}$ emission per MWh of electricity. The difference between $L C O E_{\text {ref }}$ and $L C O E_{\text {retrofit }}$ derives from the capital and O\&M costs of the post-combustion unit as well as the additional cooling capacity required for $\mathrm{CO}_{2}$ capture. More details about the cost model are available in section S4 of the SI 
Table 1 Assumptions used in the retrofit cost model (for more details see section S4 of the SI)

\begin{tabular}{|c|c|}
\hline Parameter & Assumption \\
\hline \multicolumn{2}{|l|}{ NGCC Unit } \\
\hline Other air pollution control & None \\
\hline Cooling technology ${ }^{a}$ & Wet tower \\
\hline \multicolumn{2}{|l|}{ Fuel } \\
\hline Natural gas price & $\$ 3 / \mathrm{MMBtu}(\$ 2.84 / \mathrm{GJ})$ \\
\hline Natural gas Higher Heating Value (HHV) & $22,442 \mathrm{Btu} / \mathrm{lb}$ natural gas (52.2 MJ/kg) \\
\hline $\mathrm{CO}_{2}$ to natural gas mass ratio after combustion & $2.764 \mathrm{~kg} \mathrm{CO} / \mathrm{kg}$ natural gas \\
\hline \multicolumn{2}{|l|}{ Carbon Capture System \& Retrofit Adjustments } \\
\hline System type & Amine Scrubbing \\
\hline Capture efficiency $^{a}$ & $90 \%$ \\
\hline Transportation \& Storage (T\&S) & Not included \\
\hline Retrofit energy penalty & $7 \%$ efficiency loss in power block \\
\hline Extra cooling capacity after retrofit & Yes \\
\hline \multicolumn{2}{|l|}{ Financial } \\
\hline Year Cost Reported & 2017 \\
\hline Dollar type & Constant \\
\hline Discount Rate $^{a}$ & $7.09 \%$ \\
\hline NGCC unit age reference year & 2016 \\
\hline NGCC unit economic book life (and retirement age) & 30 yrs \\
\hline Post-combustion capture unit economic book life & 30 yrs - age of NGCC unit \\
\hline Additional retrofit cost factor & $\begin{array}{l}1.15 \text { times of amine-scrubbing } \\
\text { equipment capital cost }\end{array}$ \\
\hline
\end{tabular}

${ }^{\text {a }}$ IECM default values 


\section{Learning-by-Doing:}

Historical cost trends for different technologies demonstrate a decrease in the unit cost of output as a technology is adopted and applied at increasing scales ${ }^{15-17}$. For every doubling in the cumulative production (or installed capacity), the output cost decreases by a fraction $(\varepsilon)$ :

$$
Y=a \varepsilon^{\log _{2} X}=a X^{\log _{2} \varepsilon}
$$

Where $Y$ is the unit cost of output after the cumulative production of $X$ units. Variable $a$ is the cost of a unit at the beginning of learning and $\varepsilon$ is a constant fraction for each technology. The learning rate parameter $(L R)$ is defined as:

$$
L R=1-\varepsilon
$$

The concept of learning-by-doing is widely used in academia and policy analysis to project future costs of technologies, especially in the energy and environmental domains ${ }^{17-21}$. When there is no historical learning curve for a multi-component system, one can use a component-based learning curve to break the system into its components and use available learning data for each component ${ }^{22}$. We adopted a component-based learning model to project the future cost of carbon mitigation technologies.

\section{Post-Combustion Capture Learning:}

Conventional economies of scale lower the cost for larger post-combustion units. But obtaining more experience in the implementation of a new technology by building more units, can also reduce the cost. Based on the analysis in ref. 23, a component-based learning model for capital and operating and maintenance (O\&M) costs as well as system performance were used to investigate the impact of learning on cost reductions in retrofitting.

The learning effect is applied to the cost of $\mathrm{CO}_{2}$ capture through a reduction in the capital and O\&M cost of the post-combustion capture unit and subsequently a lower LCOE after the retrofit. Therefore, the cost of electricity after retrofit ( $\left.L C O E_{\text {retrofit }}\right)$ must be broken down into its components and recalculated to reflect the lower capital and $O \& M$ cost of the post-combustion capture unit after learning.

\section{Direct Air Capture Learning:}

Direct air capture technology is in its infancy and unlike amine-scrubbing for post-combustion capture, no specific air capture technology prevails over other alternatives. From a passive capture system with 
solid sorbents to forced capture with hydroxide solution, different companies, and research groups have suggested a variety of sorbents and DAC designs ${ }^{24-26}$. As a result of this uncertainty for an emerging technology, this model is not focused on any specific DAC design. A generalized DAC cost model with two components is used in this study:

$$
\operatorname{DAC}(n)=c+r(n)
$$

$c$ is an irreducible cost component, not subject to learning, while $r$ is the reducible cost affected by the maturity of the technology ( $n$ or the implemented capacity). In other words, $c$ is the lowest possible cost for a mature DAC technology. Using equation 2, we can rewrite the cost of DAC as:

$$
\operatorname{DAC}(n)=c+r_{1} n^{\log _{2} \varepsilon}
$$

$r_{1}$ is the initial value of the reducible cost when learning begins.

It has been observed that a modular mass-produced technology (e.g. internal combustion engines, solar PV modules, etc.) experiences a higher learning rate compared to a custom-made large-scale technology (e.g. post-combustion capture units, pulverized coal power plants, etc. ${ }^{27}$. We take advantage of this observation and choose a mass-production approach of relatively smaller DAC units (1,000-ton $\mathrm{CO}_{2} /$ year) for scale-up. This leads to a larger number of DAC units produced compare to postcombustion units for natural gas-fired electricity decarbonization. 


\section{Results and Analysis}

The retrofit cost analysis model was employed to calculate the cost of post-combustion retrofits for the US NGCC fleet. Retrofit feasibility is determined by comparing the cost of post-combustion capture with that of direct air capture. The models incorporate cost reduction projections from learning-by-doing for post-combustion capture and direct air capture technologies. These reductions are included in an overall cost-optimization.

\section{Electricity and $\mathrm{CO}_{2}$ capture cost before and after retrofit:}

The total US NGCC fleet capacity in our database is about $275 \mathrm{GW}$. It generated $28 \%$ of the total US electricity in 2016. For the units considered for retrofit, the weighted average $L C O E$ is $\$ 48 / \mathrm{MWh}$. For units with a capacity factor of 0.75 and higher, the average is $\$ 37 / \mathrm{MWh}$ which agrees with the benchmark NGCC cost used in the analysis by Rubin and colleagues ${ }^{6}$.

After the retrofit, an average increase of $\$ 29 / \mathrm{MWh}$ was observed in the LCOE $(\$ 17 / \mathrm{MWh}$ LCOE increase for units with a capacity factor of 0.75 and higher). The cost of capture $(C O C)$ varies from $\$ 42$ per metric ton of carbon dioxide (ton) for the cheapest plant to over $\$ 20,000 /$ ton for the most expensive plant with an average of $\$ 80 /$ ton $(\$ 50 /$ ton average COC for units with a capacity factor of 0.75 and higher).

\section{What does retrofit feasibility mean?}

Rubin and colleagues compared the LCOE of the retrofitted units with that of a benchmark NGCC unit to determine the retrofit feasibility of coal-fired power plants ${ }^{6}$. We compare the cost of capture by postcombustion with that of direct air capture to determine the cheaper mitigation technology for each unit. DAC is currently under commercial development by several companies around the world ${ }^{28,29}$. Climeworks has already achieved a capture cost of $\$ 500-\$ 600 / \operatorname{ton}^{30}$ and Carbon Engineering estimated \$94-\$232 per ton of $\mathrm{CO}_{2}$ for their commercial plant ${ }^{31}$. To account for uncertainty, we assumed a highend DAC cost of $\$ 550 /$ ton based on Climeworks' report and a low-end cost of $\$ 100 /$ ton based on Carbon Engineering's future plant. Based on the cost of post-combustion capture, NGCC units are categorized into three groups: below $\$ 100 /$ ton, below $\$ 550 /$ ton, and above $\$ 550 /$ ton.

\section{The Retrofit potential of the existing NGCC fleet:}

Figure 1 illustrates the results of retrofit cost analysis and comparison with the cost of DAC. Figure 1a shows the cumulative distribution of $C O C$ for those NGCC units that are considered for retrofit. The cost 
of post-combustion capture for about $60 \%$ of the NGCC units in this analysis is less than $\$ 100 /$ ton and $95 \%$ of the units have a COC lower than $\$ 550 /$ ton. Note that the percentage values are based on the number of NGCC units considered for retrofit and not all the units. As mentioned in the Material and Methods section, we assumed a constant natural gas price at $\$ 3 / \mathrm{MMBtu}$. The Sensitivity of these results to the price of natural gas is investigated in section S5 of the SI.
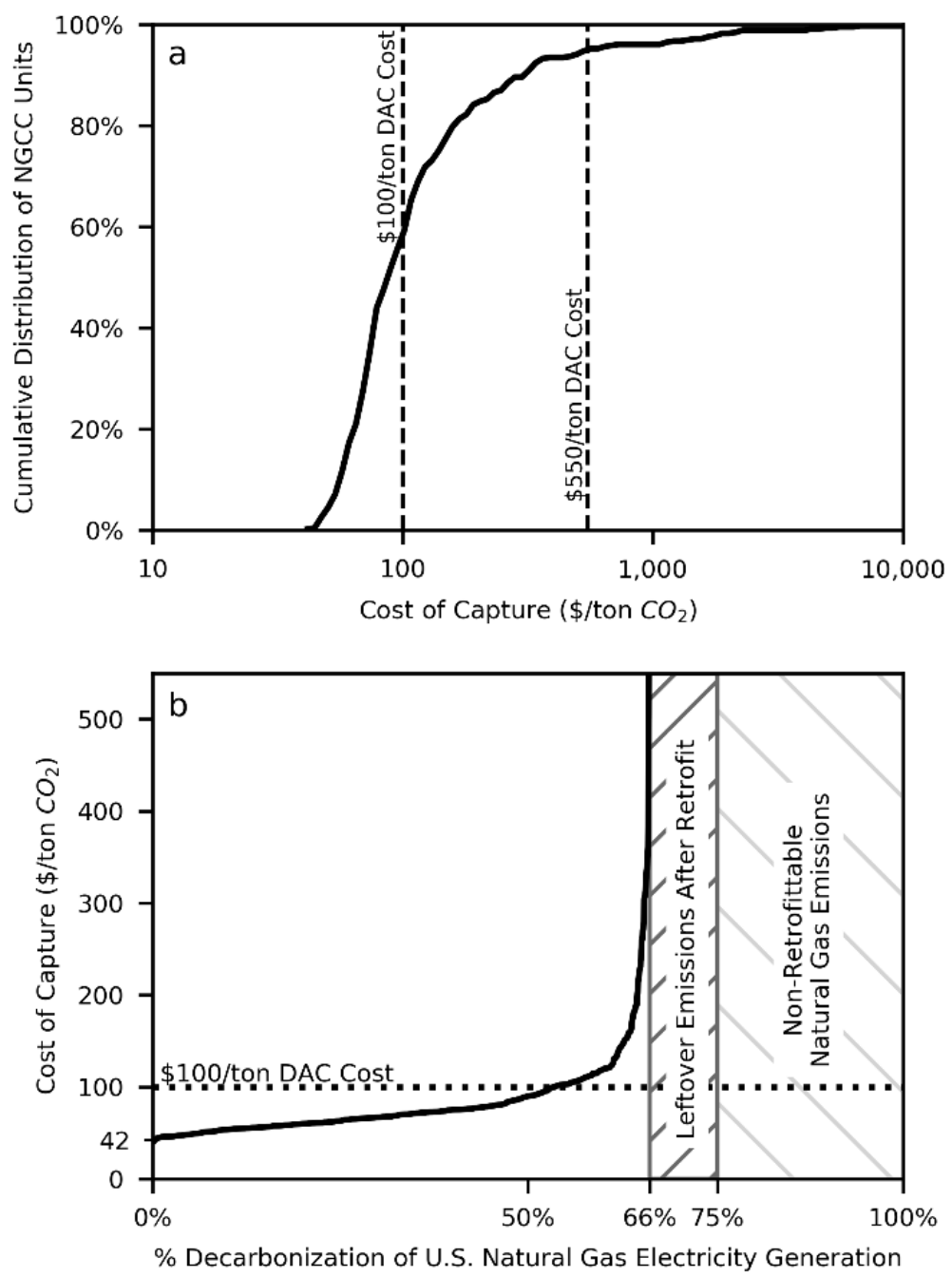

Figure 1 a) cumulative distribution of the cost of $\mathrm{CO}_{2}$ capture for the NGCC units considered for retrofit against the cost of captured $\mathrm{CO}_{2}$. Vertical lines show the two DAC cost scenarios from Climeworks and Carbon Engineering. b) cost of capture plotted against the percentage of decarbonization of natural gas-based electricity generation. Starting from the cheapest NGCC unit, the decarbonization cost goes up, as the remaining NGCC units become harder to retrofit. Retrofitting all retrofittable units result in a 66\% decarbonization. The remaining emissions combine the residual emissions after post-combustion capture of the retrofitted units (hatched area) and the emission from non-retrofittable natural gas units (cross-hatched). 
The horizontal axis in Figure $1 \mathrm{~b}$ represents the total $\mathrm{CO}_{2}$ emissions from natural gas electricity generation in the US. The black curve shows the increase in the cost of carbon capture as more NGCC units are retrofitted. The cost of capture for the most suitable unit for retrofit is $\$ 42 /$ ton. Units are sorted based on their cost of retrofit and retrofitting each consecutive unit increases the level of decarbonization of the fleet as well as the cost of capture. The cross-hatched area representing units that cannot be retrofitted contributes $25 \%$ of the total $\mathrm{CO}_{2}$ emissions from natural gas plants. These include all non-NGCC types of units, among them NGCC units smaller than $25 \mathrm{MW}$ or older than 25 years. The hatched area represents the residual emissions of the retrofitted units.

About $55 \%$ of the emissions can be captured at a price below $\$ 100 /$ ton; however, the cost of capture increases to over $\$ 20,000 /$ ton as one approaches $66 \%$ decarbonization. Direct air capture, at $\$ 550 /$ ton, is cheaper than post-combustion capture for the last few plants. The remaining $34 \%$ of emissions can only be captured by DAC, even at $\$ 550$ per ton. If DAC costs drop to $\$ 100 /$ ton, this technology could effectively address $45 \%$ of the total natural gas emissions. This exceeds 250 million tons of $\mathrm{CO}_{2}$ annually. As mentioned before, the cost of $\mathrm{CO}_{2}$ transportation is not included in this analysis. The concentration of $\mathrm{CO}_{2}$ in the air is roughly constant everywhere, therefore, DAC can be implemented at the site of storage or utilization which eliminates the cost of $\mathrm{CO}_{2}$ transportation ${ }^{32}$. The cost of transportation for postcombustion capture depends on a unit's location and its distance from a $\mathrm{CO}_{2}$ storage or utilization site. Calculating the unit-specific cost of transportation is out of the scope of this work; however, considering the location of the US NGCC units provides useful insights. Figure 2 illustrates that most of the NGCC generation capacity in the continental United States is concentrated along the West Coast and the East Coast. Southern states also host a large number of NGCC units. The cost of transportation per ton of $\mathrm{CO}_{2}$ is lower when a large generation capacity is concentrated in an area. For the isolated generating units in the middle of the country, however, the cost of transportation is likely higher. As a result, some plants with a relatively low cost of capture may not be retrofittable due to the high cost of $\mathrm{CO}_{2}$ transport (e.g., units labeled with a red star). 


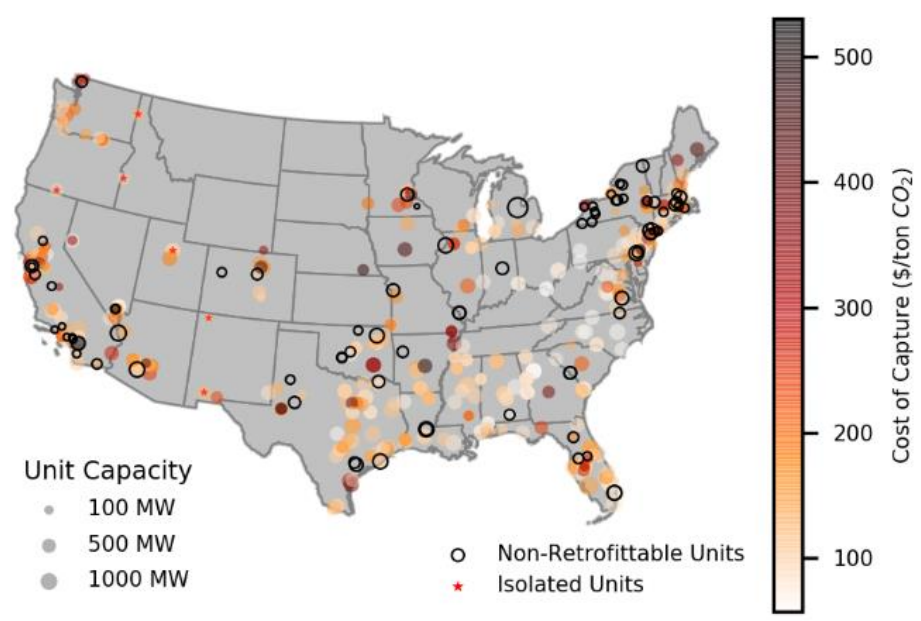

Figure 2 Distribution of the existing NGCC fleet in the continental United States. The size of bubbles represents the relative size of the units' capacity.

\section{Identifying feasibility characteristics:}

The box plots shown in Figure 3 are useful for identifying the impact of the key characteristics considered in our retrofit cost calculations on the cost of $\mathrm{CO}_{2}$ capture. We consider units with a cost of capture below $\$ 100 /$ ton as likely retrofittable and those with the cost of capture above $\$ 550 /$ ton are likely to be non-retrofittable. Retrofittable units demonstrate a higher median in nameplate capacity, net efficiency and capacity factor and a lower median in age. The interquartile range (IQR) values for retrofittable and non-retrofittable units are very well separated except for unit age. The age IQR for the retrofittable units is between 10 and 14, while non-retrofittable units have an IQR between 15 and 23. The age range overlap between the clusters is more evident when units below $\$ 550 /$ ton are compared with those above $\$ 550 /$ ton. In other words, the cost of retrofit is weakly correlated with units' age except for plants older than 20 years. Comparing the retrofittable and non-retrofittable units by their capacity factor, on the other hand, distinctly separates the two clusters. No generating unit with a capacity factor lower than 0.2 is categorized as retrofittable.

Based on the results in Figure 3 retrofittable NGCC units are larger than $350 \mathrm{MW}$, younger than 15 years, have a net efficiency higher than $42 \%$ and a capacity factor higher than 0.5 . 

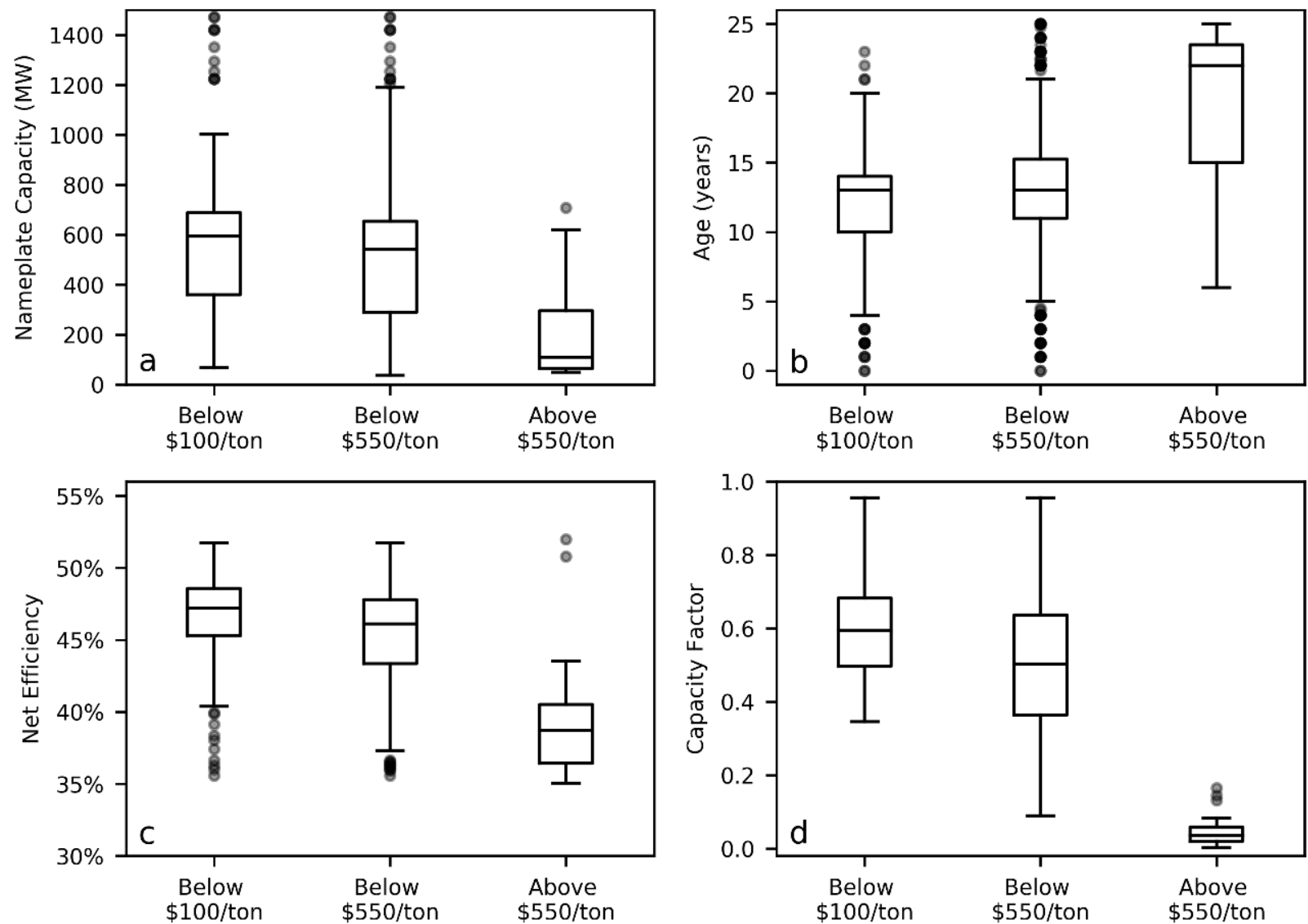

Figure 3 Box plots to display the distribution of each key attribute for clusters of post-combustion capture cost (i.e. below $\$ 100 /$ ton or retrofittable, below $\$ 500 /$ ton, and above $\$ 550 /$ ton or non-retrofittable). a) Units' nameplate capacity distribution for each cost category. b) Units' age distribution for each cost category. c) Units' net efficiency for each cost category. d) Unit's capacity factor for each cost category.

\section{Learning-by-doing:}

To incorporate the impact of learning in post-combustion capture, the learning curve from equation 2 was used to calculate the cost reduction for each cost component of an amine scrubber, i.e., the capital $(\$ / M W)$, fixed O\&M (\$/MW/yr) and variable O\&M (\$/MWh). A learning curve is also applied to the size of the energy penalty of the amine scrubber ${ }^{23}$. Applying learning formulas to generating units is complicated by the fact that different units use slightly different capture system, with different initial capital and O\&M costs at the beginning of the learning curve.

To address this issue, van den Broek et al..$^{23}$ assumed that capital and O\&M cost for all units are the same if normalized for unit output or unit capacity (see Table 5 of the article by van den Broek and colleagues). In this analysis, instead of one data point, we bounded each cost component by an interval. 
To do so, we calculated an average and standard deviation for each cost component for all the retrofitted NGCC units. Then, for each cost component, we used a range between 1.5 standard deviations below and above the average. We then recalculated an upper and a lower cost of retrofit for each unit using this range of uncertainty. These bounds provide a common ground for all units to apply the learning equation (see section S6 of the SI). Since the cost of retrofit for each plant is between the simplified upper and lower estimates, the cost of retrofit after learning falls within the upper and lower learning range as well. Included in the learning model is a reduction in the initial energy penalty with an initial value of $7 \%$ net efficiency loss.

The literature suggests that learning should be taken into account only after a certain amount of experience has been gained before the widespread commercial implementation of a technology ${ }^{19,23}$. Some papers propose that there also exists an end point for the projected learning curve $^{8}$. Similar to Rubin and colleagues ${ }^{19}$, we assumed a pre-learning phase equivalent to the first 3 GW NGCC capacity retrofitted. The learning end point is not considered in this analysis for post-combustion, but it is included in the direct air capture analysis. The range of cost components, as well as learning rates for the amine-scrubbing system, are summarized in Table 2. Learning values for the amine system are collected from ref 23.

Table 2 Range of cost components, learning rates and other assumptions used for post-combustion retrofit and direct air capture

\begin{tabular}{|c|c|c|}
\hline Parameter & Value & Learning Rate \\
\hline \multicolumn{3}{|c|}{ Amine-scrubbing post-combustion capture } \\
\hline Retrofit energy penalty & 7\% efficiency loss in power block & $2 \%-7 \%$ \\
\hline Capital cost ${ }^{a}$ & $\$ 550-\$ 1090$ per kW-net power ${ }^{b}$ & $6 \%-17 \%$ \\
\hline Fixed $O \& M$ cost $^{a, c}$ & $\$ 5-\$ 50$ per kW-net power per year & $6 \%-17 \%$ \\
\hline Variable $O \& M$ cost $^{a}$ & $\$ 2-\$ 4.2$ per MWh-electricity & $10 \%-20 \%$ \\
\hline Pre-learning phase installed capacity & 3 GW of NGCC capacity & N/A \\
\hline \multicolumn{3}{|c|}{ Direct Air Capture } \\
\hline Initial DAC cost & $\$ 100-\$ 550 /$ ton & N/A \\
\hline Initial reducible cost $\left(r_{1}\right)$ & $\$ 50-\$ 450 /$ ton & $10 \%-20 \%$ \\
\hline Irreducible Cost $(c)$ & $\$ 50-\$ 100 /$ ton & $0 \%$ \\
\hline DAC Device Capacity & 1,000 ton /year & N/A \\
\hline
\end{tabular}




\begin{tabular}{|l|l|l|}
\hline Pre-learning phase installed capacity & First 60 units & N/A \\
\hline
\end{tabular}

a Values range between 1.5 standard deviations below and above the mean for all of the considered NGCC units.

${ }^{\mathrm{b}}$ The capital cost range in this table includes the 1.15 multiplier accounting for the additional difficulty of a retrofit.

The area shaded grey in Figure 4a illustrates the probable range of post-combustion capture cost with learning. The positive slope of the curves at the beginning of post-combustion implementation (a very short section at the left-hand side of the curve) demonstrates the pre-learning phase. Learning starts after retrofitting $3 \mathrm{GW}$ of NGCC capacity (equivalent to the first 6 NGCC units). The pre-learning phase is an opportunity for technology practitioners to learn through trial and error in the early stage of the technology adaptation while no cost reduction is achieved. After the pre-learning phase until about $50 \%-65 \%$ decarbonization level, the cost of capture is roughly constant and below $\$ 100 /$ ton. Cost reductions from learning effectively balance out cost increases from retrofitting less-suitable units. After that point, the cost of $\mathrm{CO}_{2}$ capture starts increasing rapidly, going beyond $\$ 1000 /$ ton at $66 \%$ decarbonization. As part of the model assumption, post-combustion capture cannot go beyond $66 \%$ decarbonization since the $\mathrm{CO}_{2}$ capture efficiency is set to $90 \%$ and some NGCC units as well as all other non-NGCC units are deemed non-retrofittable.

Similarly, to integrate DAC learning into the model, an upper and a lower limit of initial reducible cost $\left(r_{1}\right)$ and irreducible cost $(c)$ were used (equation 3). Given the fact that modular technologies such as photovoltaic solar modules have generally demonstrated a higher learning rate ${ }^{27}$, two learning scenarios with learning rate values of $10 \%$ and $20 \%$ are employed for direct air capture. Table 2 above, also summarizes the assumptions in the cost reduction analysis of DAC. 

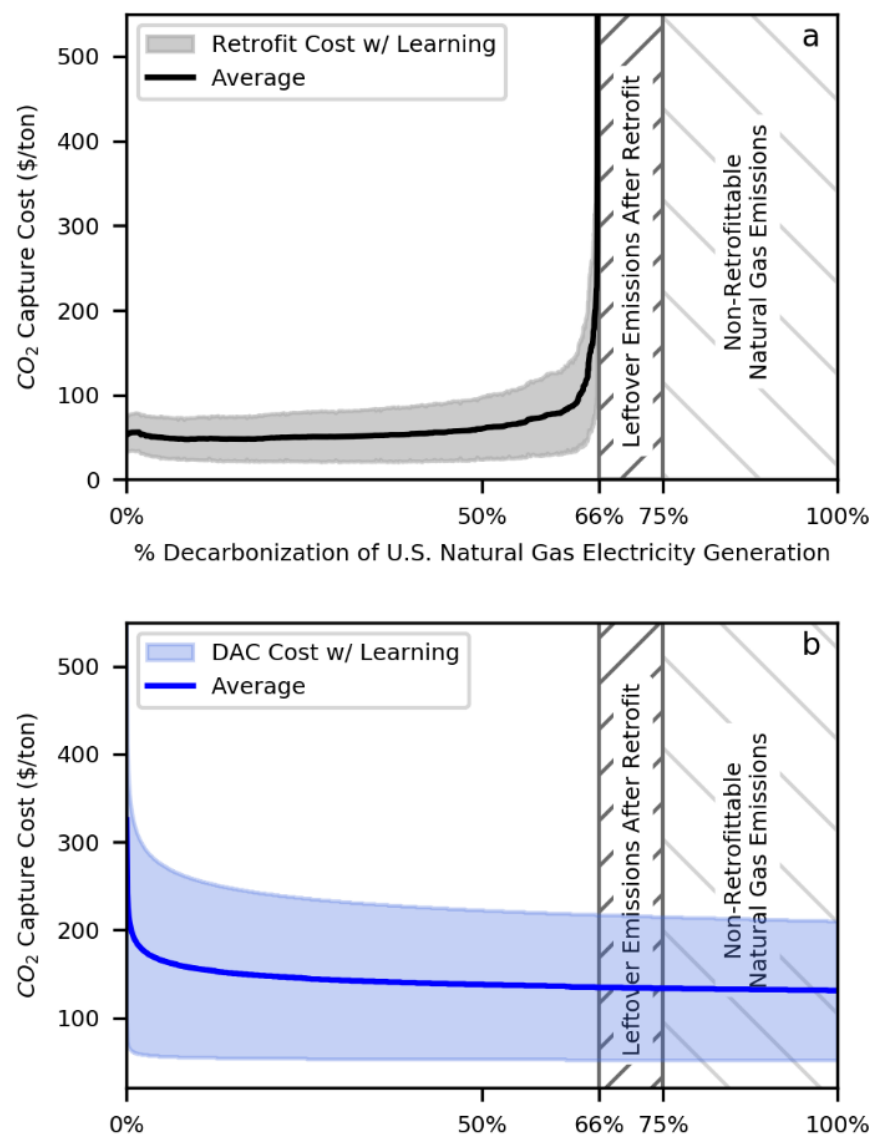

$\%$ Decarbonization of U.S. Natural Gas Electricity Generation Retrofit Limit

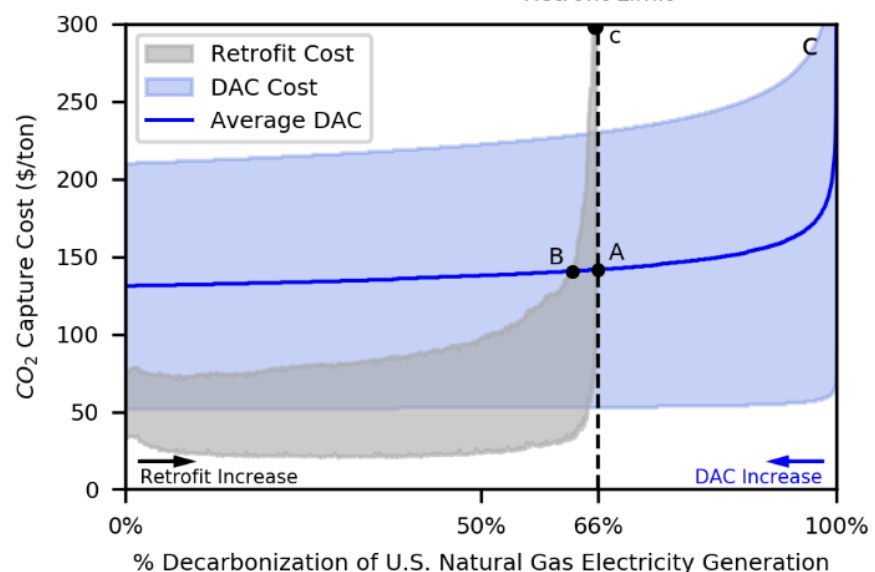

Figure 4 Cost of $\mathrm{CO}_{2}$ capture plotted against decarbonization level considering the impact of learning-by-doing for a) postcombustion retrofit, b) direct air capture. c) 100\% decarbonization plan for the US natural gas power plant fleet by implementing post-combustion capture retrofit and direct air capture. The effect of learning-by-doing on the cost of capture is accounted for both technologies. 
Figure $4 \mathrm{~b}$ shows how the cost of direct air capture decreases if is implemented for decarbonization of US natural gas-fired electricity. Compared to amine scrubbing, DAC is a young technology, therefore, a more conservative pre-learning phase equivalent to 60 units (versus 6 units for amine-scrubbing) was used in the model. In the case of DAC, the results are extremely sensitive to the pre-learning phase, as it

greatly reduces the number of subsequent doublings. However, because of the smaller capture capacity of individual units, it is hard to see the pre-learning phase in the graph. As shown in the figure, capturing $\mathrm{CO}_{2}$ directly from the air, regardless of the emission source, makes it possible for DAC to take decarbonization beyond the technological and economical limit of post-combustion capture and achieve a $100 \%$ decarbonization. The cheapest DAC scenario reaches the minimum cost (irreducible cost component) immediately after the beginning of large-scale implementation, while the expensive scenario reaches a final cost of $\$ 210 /$ ton.

\section{The optimum mix of DAC and post-combustion capture:}

Figure $4 c$ combines the two cost curves in Figure $4 a$ and $b$ into one plot. It reflects the DAC cost curve because we assume DAC is first implemented for those plants that are not retrofittable. In effect, DAC's cost curve starts at the right-hand side of the plot. The overlap between the shaded areas demonstrates that in some situations DAC could be competitive with post-combustion capture. The learning approaches are quite different. Even assuming very conservative learning rates for DAC based on mass production, the modular mass production of DAC is far more effective than the expensive and long-term capital investment for custom-made post-combustion capture units.

In this analysis, at least one-third of the total emission can only be captured by DAC. This is equivalent to about 200 million tons of $\mathrm{CO}_{2}$ annually captured by 200,000 DAC units. The cheapest DAC scenario is across the board cheaper than the most expensive retrofit scenario. If one assumes the cheapest scenarios for both technologies, DAC would account for more than one-third of the emission capture.

Assuming that DAC is the sole option for decarbonization of the non-retrofittable units, an early implementation of this technology for these plants will also reduce the cost of capture for the retrofittable portion. As an example, consider the average DAC cost scenario shown with the blue curve in Figure 4c. The initial cost of $\$ 325 /$ ton is the starting point and when employed for one-third of the emission, the technology becomes relatively mature at the cost of $\$ 140 /$ ton (point A). If the cost of postcombustion retrofit follows the lower limit scenario, retrofits will be cheaper than DAC to address the rest of the emissions and DAC does not penetrate beyond 34\%. On the other hand, if the upper limit 
reflects the cost of retrofitting, the mature DAC becomes cheaper than retrofitting the last few retrofittable NGCC units and DAC can penetrate up to point B (38\% DAC share). This effectively reduces the total cost of decarbonization (saving would be equal to the grey shaded area between $A, B$, and C). DAC's penetration and the resulting cost reduction in decarbonization can be different depending on where the actual learning curves for DAC and post-combustion capture end up. It is worth noting that the technology implementation timeline is crucial and such a saving in decarbonization happens only if DAC becomes cheaper than its current price through early implementations.

\section{The impact of retrofit decarbonization on the grid:}

Both post-combustion capture and direct air capture consume electricity and heat. The post-combustion retrofit energy penalty reduces the electricity output of an NGCC unit by $10-20 \%$ and large-scale implementation of this technology significantly lowers the amount of available capacity in the grid. To compensate for this loss, some consider employing auxiliary gas-fired generation capacities for electricity and thermal energy consumption of post-combustion capture. This increases the LCOE and cost of capture ${ }^{6,33}$. Alternatively, a flexible post-combustion capture design may make it possible to turn off the capture unit (entirely ${ }^{34,35}$ or only the energy-intensive parts, i.e. sorbent regeneration and $\mathrm{CO}_{2}$ compression ${ }^{36,37}$ ) during peak electricity demand hours. However, such solutions come with technical challenges ${ }^{38}$ and high cost of storage for excess sorbent when regeneration of the stored sorbent happens off peak ${ }^{39}$.

Direct air capture generally offers more flexibility in terms of its source of electricity. Shifting DAC's operation to off-peak hours is not as challenging as post-combustion capture since DAC is not attached to a generating unit. Unlike post-combustion capture, a disruption in the operation of DAC does not emit more $\mathrm{CO}_{2}$. Additionally, flexibility in the geographical location of DAC makes it possible to partially or entirely obtain the necessary electricity from off-grid solar or wind electricity.

Post-combustion capture and DAC increase the total amount of fuel consumption (and as a result additional $\mathrm{CO}_{2}$ emission) when they obtain their electricity from fossil-based sources. The horizontal axes in Figures $1 \mathrm{~b}, 4$ do not take this additional $\mathrm{CO}_{2}$ into account and percentage values are relative to 2016 total natural gas-related $\mathrm{CO}_{2}$ emissions. In the case of post-combustion capture, most of the additional emission is captured by the unit itself but the overall capture rate is less than $90 \%$ (it is typically about $88 \%)$. 
The additional $\mathrm{CO}_{2}$ emissions increase the cost of $\mathrm{CO}_{2}$ transportation for post-combustion capture, while DAC does not incur this extra cost. Moreover, as mentioned earlier, DAC offers more flexibility and can obtain its electricity from carbon-free sources which significantly lowers the additional fuel consumption. 


\section{Final Remarks:}

Direct air capture is identified as one of the most promising negative emission technologies in terms of scalability and minimizing environmental risks ${ }^{40}$. By comparing the cost of DAC with post-combustion retrofit, this study investigates DAC's potential for electricity decarbonization which is beyond negative emissions. In a scenario where complete decarbonization of the existing US natural gas power plant fleet is desired, we exploit some unique features of DAC and identify DAC as a backup if the mainstream technology (post-combustion capture) fails, either technologically or economically.

We found that the capacity factor is the most important attribute affecting the cost of post-combustion capture. Beyond routine maintenance or sudden failures of a generating unit, exogenous economic factors such as electricity demand and the dispatch cost of competitive power plants determine the capacity factor of a unit. When compared to post-combustion retrofit, DAC with the cost of $\$ 550$ per ton $\mathrm{CO}_{2}$ will be competitive to capture more than one-third of the total $\mathrm{CO}_{2}$ emission from natural gas-fired power plants. At a cost of $\$ 100$ per ton, DAC can potentially capture up to $45 \%$ of the total emission more economically than retrofit.

When the impact of learning-by-doing is considered, differences in nature and scale-up approaches of the two technologies resulted in a more dramatic cost reduction for DAC. To keep the model simple and minimize assumptions, this analysis does not account for elapsed time and assumes a static system of NGCC units. In reality, however, learning happens over time. Time-dependent factors such as fluctuation in electricity demand as well as new policies and investment in R\&D for each technology can significantly affect the cumulative installed capacity and consequently cost reduction by learning. Incorporating all of these different factors increases the complexity of the model yet does not guarantee an improvement in its accuracy.

The scope of this analysis is narrowly focused on $\mathrm{CO}_{2}$ emissions from natural gas. The impact of learning for DAC would be even more dramatic if decarbonization of other sectors (e.g. transportation) are included. Learning-by-doing for different mitigation technologies used in different sectors (e.g. post-, pre-, and oxyfuel combustion in electricity generation, or batteries in transportation) happens in parallel since most of these technologies are a solution for reducing emissions of a specific sector. DAC, on the other hand, would experience cumulative learning since it is a global decarbonization solution for any kind of $\mathrm{CO}_{2}$ emissions. 
The Post-combustion cost calculation in this analysis is based on retrofitting each NGCC unit separately. However, Rubin and colleagues observed that lumping multiple units in a plant and capturing their emissions by a large post-combustion unit can also lower $\operatorname{cost}^{6}$. This would compete with cost reductions from learning, and for sake of simplicity has not been included. Another simplification in the model is the assumption that the change due to $\mathrm{CO}_{2}$ capture in the LCOE does not affect the dispatch merit order of the units or their future generation levels.

Although post-combustion capture appears to be an ideal choice for $\mathrm{CO}_{2}$ reduction from coal and natural gas power plants, it may not be the most cost-effective method in all circumstances. Our results indicate that a low capacity factor leads to a high cost of post-combustion capture, even for a new power plant. An increasing penetration of non-dispatchable renewables (wind and solar electricity) into the electricity grid will result in lower capacity factors of dispatchable generating plants including coal and natural gas-fired units. The impact of high renewable integration on the dispatchable generating units is already evident in California and Texas ${ }^{41,42}$. Direct air capture units, on the other hand, operate autonomously regardless of a specific power plant's utilization level.

\section{Associated Content}

Supporting Information

Power plants information datamining; Machine learning to estimate missing generating units' information; Cumulative generation based on capacity factor; Developing a retrofit cost analysis model; Results sensitivity to natural gas price; The impact of learning-by-doing on the costs

\section{Acknowledgment:}

This project was supported by Shell's New Energy Research and Technology (NERT) Program for this work. We would like to acknowledge the invaluable input of NERT's Dense Energy Carriers team (DEC) during the course of this work. We are grateful for the great support and valuable remarks from Mr. Robert Page at the Arizona State University's Center for Negative Carbon Emissions in our power plant cost modeling. One of the authors declares his interest as a technical advisor in a startup company that licensed specific technology for direct air capture from Arizona State University. 


\section{References:}

(1) US EPA, O. Inventory of U.S. Greenhouse Gas Emissions and Sinks https://www.epa.gov/ghgemissions/inventory-us-greenhouse-gas-emissions-and-sinks (accessed Oct 15, 2019).

(2) EIA - Electricity Data https://www.eia.gov/electricity/monthly/epm_table_grapher.php?t=epmt_1_1 (accessed Nov 21, 2019).

(3) Victor, D. G.; Akimoto, K.; Kaya, Y.; Yamaguchi, M.; Cullenward, D.; Hepburn, C. Prove Paris Was More than Paper Promises. Nature 2017, 548 (7665), 25-27. https://doi.org/10.1038/548025a.

(4) A Technical, Economic, and Environmental Assessment of Amine-Based CO2 Capture Technology for Power Plant Greenhouse Gas Control | Environmental Science \& Technology https://pubs.acs.org/doi/abs/10.1021/es0158861 (accessed Oct 15, 2019).

(5) Masson-Delmotte, V.; Zhai, P.; Pörtner, H. O.; Roberts, D.; Skea, J.; Shukla, P. R.; Pirani, A.; Moufouma-Okia, W.; Péan, C.; Pidcock, R.; et al. IPCC, 2018: Summary for Policymakers. In: Global Warming of $1.5^{\circ} \mathrm{C}$; World Meteorological Organization, Geneva, Switzerland, 2018 ; p 32.

(6) Zhai, H.; Ou, Y.; Rubin, E. S. Opportunities for Decarbonizing Existing U.S. Coal-Fired Power Plants via CO2 Capture, Utilization and Storage. Environ. Sci. Technol. 2015, 49 (13), 7571-7579. https://doi.org/10.1021/acs.est.5b01120.

(7) US Environmental Protection Agency. Carbon Pollution Emission Guidelines for Existing Stationary Sources: Electric Utility Generating Units; 40 CFR Part 60. 2014.

(8) Rubin, E. S. Understanding the Pitfalls of CCS Cost Estimates. International Journal of Greenhouse Gas Control 2012, 10, 181-190. https://doi.org/10.1016/j.ijggc.2012.06.004.

(9) Rubin, E. S.; Zhai, H. The Cost of Carbon Capture and Storage for Natural Gas Combined Cycle Power Plants. Environ. Sci. Technol. 2012, 46 (6), 3076-3084. https://doi.org/10.1021/es204514f.

(10) Emissions \& Generation Resource Integrated Database (EGRID).; 2016.

(11) Lackner, K. S. The Thermodynamics of Direct Air Capture of Carbon Dioxide. Energy 2013, 50, 3846. https://doi.org/10.1016/j.energy.2012.09.012.

(12) Carnegie Mellon University. Integrated Environmental Control Model (IECM); 2018.

(13) Middleton, R. S.; Bielicki, J. M. A Scalable Infrastructure Model for Carbon Capture and Storage: SimCCS. Energy Policy 2009, 37 (3), 1052-1060. https://doi.org/10.1016/j.enpol.2008.09.049.

(14) Metz, B.; Davidson, O.; De Coninck, H.; Loos, M.; Meyer, L. IPCC, 2005: Special Report on Carbon Dioxide Capture and Storage; Intergovernmental Panel on Climate Change, Geneva (Switzerland), 2005.

(15) Wright, T. P. Factors Affecting the Cost of Airplanes. Journal of the Aeronautical Sciences 1936, 3 (4), 122-128. https://doi.org/10.2514/8.155.

(16) McDonald, A.; Schrattenholzer, L. Learning Rates for Energy Technologies. Energy Policy 2001, 29 (4), 255-261. https://doi.org/10.1016/S0301-4215(00)00122-1.

(17) Nemet, G. F. Beyond the Learning Curve: Factors Influencing Cost Reductions in Photovoltaics. Energy Policy 2006, 34 (17), 3218-3232. https://doi.org/10.1016/j.enpol.2005.06.020.

(18) Rubin, E.; Yeh, S.; Hounshell, D.; Taylor, M. R. Experience Curves for Power Plant Emission Control Technologies. 2004. https://doi.org/10.1184/R1/6073118.v1.

(19) Rubin, E. S.; Yeh, S.; Antes, M.; Berkenpas, M.; Davison, J. Use of Experience Curves to Estimate the Future Cost of Power Plants with CO2 Capture. International Journal of Greenhouse Gas Control 2007, 1 (2), 188-197. https://doi.org/10.1016/S1750-5836(07)00016-3.

(20) Jamasb, T. Technical Change Theory and Learning Curves: Patterns of Progress in Electricity Generation Technologies. The Energy Journal 2007, 28 (3), 51-71. 
(21) Schmidt, O.; Hawkes, A.; Gambhir, A.; Staffell, I. The Future Cost of Electrical Energy Storage Based on Experience Rates. Nature Energy 2017, 2 (8), 17110.

https://doi.org/10.1038/nenergy.2017.110.

(22) Rubin, E. S.; Azevedo, I. M. L.; Jaramillo, P.; Yeh, S. A Review of Learning Rates for Electricity Supply Technologies. Energy Policy 2015, 86, 198-218.

https://doi.org/10.1016/j.enpol.2015.06.011.

(23) van den Broek, M.; Hoefnagels, R.; Rubin, E.; Turkenburg, W.; Faaij, A. Effects of Technological Learning on Future Cost and Performance of Power Plants with CO2 Capture. Progress in Energy and Combustion Science 2009, 35 (6), 457-480. https://doi.org/10.1016/j.pecs.2009.05.002.

(24) Sanz-Pérez, E. S.; Murdock, C. R.; Didas, S. A.; Jones, C. W. Direct Capture of CO2 from Ambient Air. Chem. Rev. 2016, 116 (19), 11840-11876. https://doi.org/10.1021/acs.chemrev.6b00173.

(25) Shi, X.; Xiao, H.; Azarabadi, H.; Song, J.; Wu, X.; Chen, X.; Lackner, K. S. Sorbents for Direct Capture of $\mathrm{CO} 2$ from Ambient Air. Angewandte Chemie International Edition $O$ (ja). https://doi.org/10.1002/anie.201906756.

(26) Azarabadi, H.; Lackner, K. S. A Sorbent-Focused Techno-Economic Analysis of Direct Air Capture. Applied Energy 2019, 250, 959-975.

(27) Dahlgren, E.; Göçmen, C.; Lackner, K.; Ryzin, G. van. Small Modular Infrastructure. The Engineering Economist 2013, 58 (4), 231-264. https://doi.org/10.1080/0013791X.2013.825038.

(28) Bourzac, K. Emissions: We Have the Technology. Nature 2017, 550, S66-S69. https://doi.org/10.1038/550S66a.

(29) Cressey, D. Commercial Boost for Firms That Suck Carbon from Air. Nature News 2015, 526 (7573), 306.

(30) Gertner, J. The Tiny Swiss Company That Thinks It Can Help Stop Climate Change. The New York Times. February 12, 2019.

(31) Keith, D. W.; Holmes, G.; St. Angelo, D.; Heidel, K. A Process for Capturing CO2 from the Atmosphere. Joule 2018, 2 (8), 1573-1594. https://doi.org/10.1016/j.joule.2018.05.006.

(32) Elliott, S.; Lackner, K. S.; Ziock, H. J.; Dubey, M. K.; Hanson, H. P.; Barr, S.; Ciszkowski, N. A.; Blake, D. R. Compensation of Atmospheric $\mathrm{CO} 2$ Buildup through Engineered Chemical Sinkage. Geophysical Research Letters 2001, 28 (7), 1235-1238. https://doi.org/10.1029/2000GL011572.

(33) Davison, J. Performance and Costs of Power Plants with Capture and Storage of CO2. Energy 2007, 32 (7), 1163-1176. https://doi.org/10.1016/j.energy.2006.07.039.

(34) Chalmers, H.; Leach, M.; Lucquiaud, M.; Gibbins, J. Valuing Flexible Operation of Power Plants with CO2 Capture. Energy Procedia 2009, 1 (1), 4289-4296. https://doi.org/10.1016/j.egypro.2009.02.241.

(35) Cohen, S. M.; Rochelle, G. T.; Webber, M. E. Turning CO2 Capture On and Off in Response to Electric Grid Demand: A Baseline Analysis of Emissions and Economics. J. Energy Resour. Technol 2010, 132 (2). https://doi.org/10.1115/1.4001573.

(36) Chalmers, H.; Gibbins, J. Initial Evaluation of the Impact of Post-Combustion Capture of Carbon Dioxide on Supercritical Pulverised Coal Power Plant Part Load Performance. Fuel 2007, 86 (14), 2109-2123. https://doi.org/10.1016/j.fuel.2007.01.028.

(37) Chalmers Hannah; Lucquiaud Mathieu; Gibbins Jon; Leach Matt. Flexible Operation of Coal Fired Power Plants with Postcombustion Capture of Carbon Dioxide. Journal of Environmental Engineering 2009, 135 (6), 449-458. https://doi.org/10.1061/(ASCE)EE.1943-7870.0000007.

(38) Lin, Y.-J.; Wong, D. S.-H.; Jang, S.-S.; Ou, J.-J. Control Strategies for Flexible Operation of Power Plant with CO2 Capture Plant. AIChE Journal 2012, 58 (9), 2697-2704.

https://doi.org/10.1002/aic.12789. 
(39) Haines, M. R.; Davison, J. E. Designing Carbon Capture Power Plants to Assist in Meeting Peak Power Demand. Energy Procedia 2009, 1 (1), 1457-1464. https://doi.org/10.1016/j.egypro.2009.01.191.

(40) Keith, D. W. Why Capture CO2 from the Atmosphere? Science 2009, 325 (5948), 1654-1655. https://doi.org/10.1126/science.1175680.

(41) Denholm, P.; Hand, M. Grid Flexibility and Storage Required to Achieve Very High Penetration of Variable Renewable Electricity. Energy Policy 2011, 39 (3), 1817-1830. https://doi.org/10.1016/j.enpol.2011.01.019.

(42) ISO, C. What the Duck Curve Tells Us about Managing a Green Grid. Calif. ISO, Shap. a Renewed Futur 2012, 1-4. 